\title{
Macroscopic and microscopic study of integuments on ostrich (Struthio camelus) foot
}

\author{
Rui Zhang, Songsong Ma, Xiujuan Li, \\ Gang Luo, Shuliang Xue, Jianqiao Li \\ Key Laboratory of Bionic Engineering, Ministry of Education, \\ Jilin University, Nanguan District, Changchun, 130022, People's Republic of China \\ zhangrui@jlu.edu.cn
}

Received: December 3, 2015 Accepted: May 18, 2016

\begin{abstract}
Introduction: Ostrich characteristics include fast running, of which the probable enablers have been studied. Yet little research has taken place on one anatomical feature. It is mainly the special integuments on the ostrich foot which facilitate fast running on sand, because as point of direct sand contact they bear the whole weight and provide all the forward force. This study elucidates aspects of the integuments. Material and Methods: A stereo microscope, scanning electron microscope (SEM), and confocal scanning laser microscope were used to observe these integuments. Their surface structure was shown accurately in photographs. An SEM equipped with energy dispersive spectroscopy was used to check element contents of the upper and bottom areas and those on the lateral area of the $3^{\text {rd }}$ toe. Results: The content of some chemical elements on the upper area (Mg 2.04\%, Si 0.18\%, P 1.97\%, Ca 0.59\%, and S 0.69\%) was higher than that of the bottom area $(\mathrm{Mg} \mathrm{0.14 \% ,} \mathrm{Si} 0.09 \%$, P $0.10 \%$, $\mathrm{Ca} 0.28 \%$, and S $0.90 \%$ ). Zinc was the particular element on the upper area, while sodium, chlorine, and potassium were the specific elements on the bottom area. The parts which must withstand different frictions contained different chemical compounds. Conclusion: The microscopic plane with layer-like structure and stripes may contribute to the wear-resistance of the papillae. The polygonal and prism structures are helpful to fix papillae in a firmer way.
\end{abstract}

Keywords: ostrich, foot integuments, microscopic and chemical analysis.

\section{Introduction}

Ostriches (Struthio camelus) have drawn much attention in recent years due to their various outstanding characteristics (22). They are native to Africa where there are spacious areas, treeless savannah, and endless desert. (17). As a source of protein and high-quality leather, ostriches are raised in many parts of the world, which brings considerable economic advantage. $(2,14)$. The ostrich cannot fly because of its degeneration of wingspan and absence of sternal keel to which the flight muscles could be attached $(5,10,13)$. After evolving for thousands of years, ostriches have become specialised in running. These nearly $150 \mathrm{~kg}$ birds can run steadily for $30 \mathrm{~min}$ at a speed of over $60 \mathrm{~km} / \mathrm{h}$, with each step longer than $5 \mathrm{~m}(1,12)$. In recent years, some researchers have focused on the muscles of the pelvic limb (18), meat (4), long bones (3), supra-jointed toe posture (7), articular cartilage (20), serum glycosaminoglycan and proteoglycan (11), economical bipedal running (16), and toepad from the anatomical perspective (8).

There are other scientists who have found strong relationships between plantar skin morphology and flightlessness in birds (21). However, few of them have ever studied the integuments of the foot, which provide large friction and withstand enough force to permit the ostrich to run at high speed. The large friction means that the integuments of the foot are resistant to the wear attendant on large forces. Thus this paper presents a detailed survey of the ostrich from this aspect.

\section{Material and Methods}

Imaging techniques were applied to observe the macroscopic and microscopic structure of the integuments on the foot of a two-year-old ostrich. A stereo microscope (SM), scanning electron microscope (SEM), and confocal scanning laser 
microscope (CSLM) were used for the examination according to a scrupulously prepared protocol. Images were compared in order to analyse the integuments' morphology and the energy spectrum diagram which can be easily obtained from an SEM. In this way, the different element contents specifically in the lateral region of the ostrich foot were seen.

Test specimens. The feet were taken from three two-year-old adult homebred ostriches which were bought from the slaughter house located in Harbin, Heilongjiang Province, P. R. China. The feet had not undergone any surgery and their physical morphology, especially the integuments, was in perfect condition.

Design and methods. The integuments were taken from five representative positions which form the main surface of the ostrich foot, namely, the papillae on the plantar surface of the $3^{\text {rd }}$ toe, the papillae on the plantar surface of the $4^{\text {th }}$ toe, the lateral region of the $3^{\text {rd }}$ toe, the transitional region between the $3^{\text {rd }}$ toe and the claw, and the scale on the back of the $3^{\text {rd }}$ toe (Fig. 1). Five small samples $(1 \mathrm{~cm} \times 1 \mathrm{~cm} \times 1 \mathrm{~cm})$ taken from each representative position were used as the test specimens.

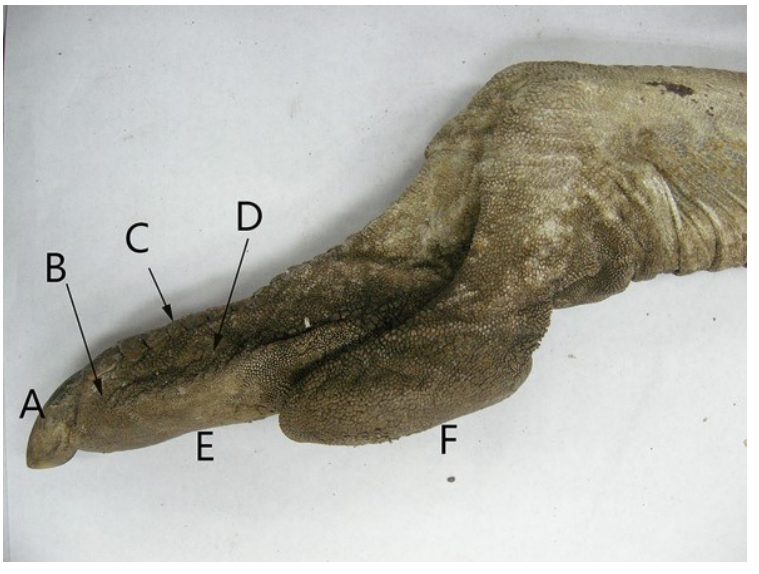

Fig. 1. Photograph of lateral view of ostrich foot

A - papillae on plantar surface of the $3^{\text {rd }}$ toe; $\mathrm{B}$ - papillae on plantar surface of the $4^{\text {th }}$ toe; $\mathrm{C}$ - transitional region between $3^{\text {rd }}$ toe and claw; D - scale on back of the $3^{\text {rd }}$ toe; $\mathrm{E}-$ lateral region of $3^{\text {rd }}$ toe

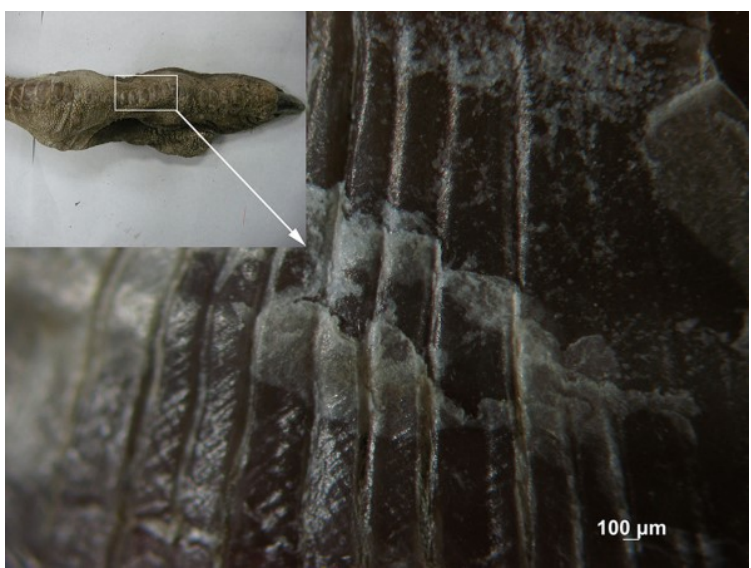

Fig. 2. Stereo microscope photograph of scale on back of $3^{\text {rd }}$ toe showing rib morphology and covers on surface $(20 \times)$
Stereo microscope. A SteREO Discovery V 12 microscope (Carl Zeiss, Germany) was used. The image analysis system resolution was 10.4 megapixels, and the operating system was Vision Rel. 4.6 (Carl Zeiss, Germany). The test specimens were washed in $30^{\circ} \mathrm{C}$ water for 4 mins and dried with blotting paper. These samples were then observed under SM.

In order to see the original part of papillae on the plantar surface of the $3^{\text {rd }}$ toe, the skin of the papillae was cut into small pieces $(1 \mathrm{~cm} \times 1 \mathrm{~cm} \times 1 \mathrm{~cm})$ after being removed from the papillae. The specimens were dried with blotting paper and put on the SM stage for examination.

Scanning electron microscope. A 1000-B SEM (Carl Zeiss, Germany) was used at $6 \mathrm{~nm}$ resolution. The test specimens were fixed on a sample holder (carousel $9 \times 9 \mathrm{~mm}$ ) and were then dried in a lyophiliser. Finally, the samples were coated with gold-palladium in a sputtering device, and put on the SEM stage as the scope operated at $5.0 \mathrm{Kv}$, observed, and photographed.

Confocal scanning laser microscope. A LEXT OLS3000 CSLM (Olympus Optical, Japan) was used. The test specimens were washed in normal saline, then the pieces were immersed in a fixative $(4 \%$ phosphofructaldolase) at $4{ }^{\circ} \mathrm{C}$ for $8 \mathrm{~h}$. Once fixed, the samples were washed three times in $0.01 \mathrm{M}$ PBS for $20 \mathrm{~min}$. After $1 \mathrm{~h}$ immersion in $20 \%$ saccharose at $4{ }^{\circ} \mathrm{C}$, the samples were put on the stage of CSLM, observed, and photographed.

\section{Results}

The scales on the $3^{\text {rd }}$ toe. The distribution of scales starts from the ankle joint position and extends to the tip of the toe. There are also some scales on the back of the $4^{\text {th }}$ toe. Scales overlap just like roofing tiles (Fig. 2). The scales are brown or grey in colour, but some scales are reddish-brown. The size of the scales varies from the tibiotarsus position to the back of the $3^{\text {rd }}$ toe. The widest part of the scale in the axial direction is $1.5 \mathrm{~cm}$ while in the radial direction the largest dimension is $3 \mathrm{~cm}$. Under SM, the scales show a light-reflecting surface and their rib morphology, with the ribs almost $200 \mu \mathrm{m}$ in width. Some white covers adhere to the surface of the scales. In every rim, there are inclined small streaks which are parallel to each other and form a 45 degree angle with the rib.

The papillae on the plantar surface of the $3^{\text {rd }}$ toe. The plantar surface of the $3^{\text {rd }}$ toe is covered with papillae. On the plantar edge of this toe, papillae spread out to the edge, but in the central part of the toe, the papillae are in the vertical direction. Distribution density of these papillae is $50-65$ papillae $/ \mathrm{cm}^{2}$ and their height is $5-12 \mathrm{~mm}$. These columnar collective papillae are old and yellow, but they are surrounded by some which are newly developed (Fig. 3A). The tips of the new ones are white and they present conical structure, while the old ones are rubbed down and present 
disperse tips. Upon scrutiny of these rubbed papillae, it is observed that there are 3-6 circles of layer-like structure (Fig. 3B). In the central part of the $3^{\text {rd }}$ toe, the shape of a single papilla resembles a cone-shaped cylinder, and the original part is a little smaller than the terminal part.

Papillae are hollow, as shown in the cross section (Fig. 4). The cross section is golden, while the internal surface is dirty red and the outside surface is white. There are three circles resembling the annual rings.

After pulling out the papillae, the initiation site of the papillae is revealed as polygonal, with each side having one convex. The distance between two polygons is approximately $500 \mu \mathrm{m}$. The longest diameter of polygons is $1359.49 \mu \mathrm{m}$; the shortest diameter is $838.64 \mu \mathrm{m}$ (Fig. 5).

Under SEM, the configuration of a single papilla is very rough (Fig. 6A). Contrastingly, with a larger amplification, the surface presents a flat and layer-like structure, with some stripes on the surface (Fig. 6B). On the surface of the middle part of the papilla, there are also flat and layer-like structures, but this surface is rougher (Fig. 7A). The root of the papilla has many wrinkles, while the stripe narrows (Fig. 7/B). From the tip to the root of the papilla, the stripe trends narrower and the surface rougher under SEM.

The papillae on the plantar surface of the $4^{\text {th }}$ toe. Papillae on the plantar surface of the $4^{\text {th }}$ toe also spread over the plantar surface and out to the edge. They are in the vertical direction in the centre of this toe. Their distribution density and height are 4360 papillae $/ \mathrm{cm}^{2}$ and $0.2-0.4 \mathrm{~cm}$ respectively. Papillae are usually yellow and their tips are cone-shaped (Fig. 8A). In contrast to the papillae on the $3^{\text {rd }}$ toe, the papillae on the $4^{\text {th }}$ toe are thinner, brighter, and their gaps are wider. These papillae are frayed slightly and their tips remain unbroken (Fig. 8B).

Under SEM, the tip of the papilla is very pointed with some fibroid structure adhering (Fig. 9A). With a larger amplification, the tip presents a disordered and rough surface (Fig. 9B). On the surface of the middle part of papilla, there are raised stripes (Fig. 10A) and on the root of the papillae, there are granules on the surface (Fig. 10B). All three surfaces of the three places are rough under the microscope.

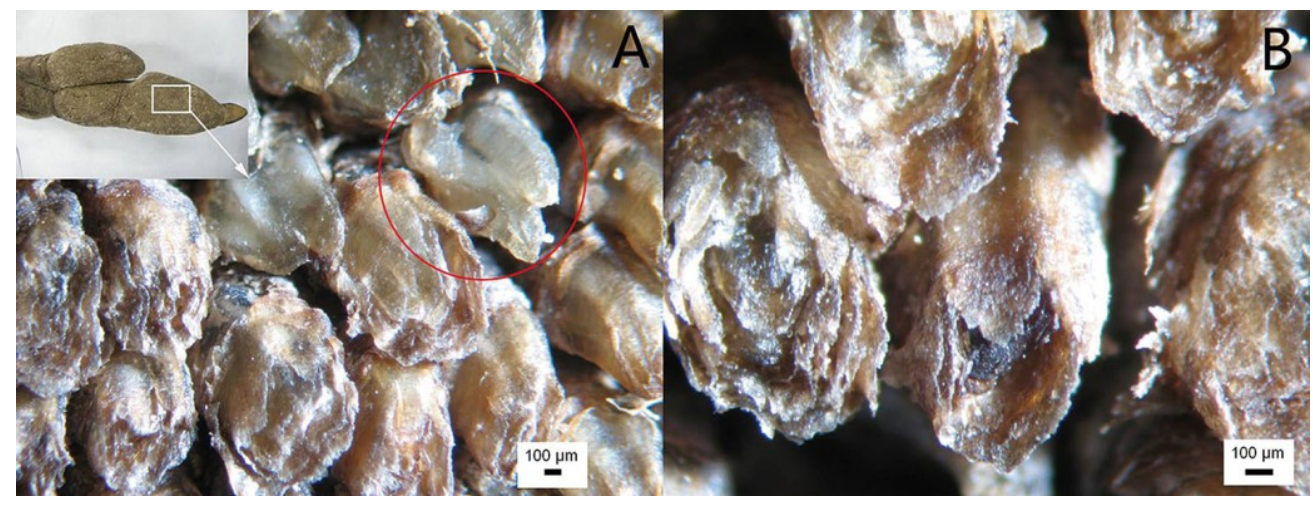

Fig. 3. SM photographs of papillae on plantar surface of $3^{\text {rd }}$ toe. A - old and newly developed columnar collective papillae (in red circle) (20×); B - stratiform top of papillae $(40 \times)$

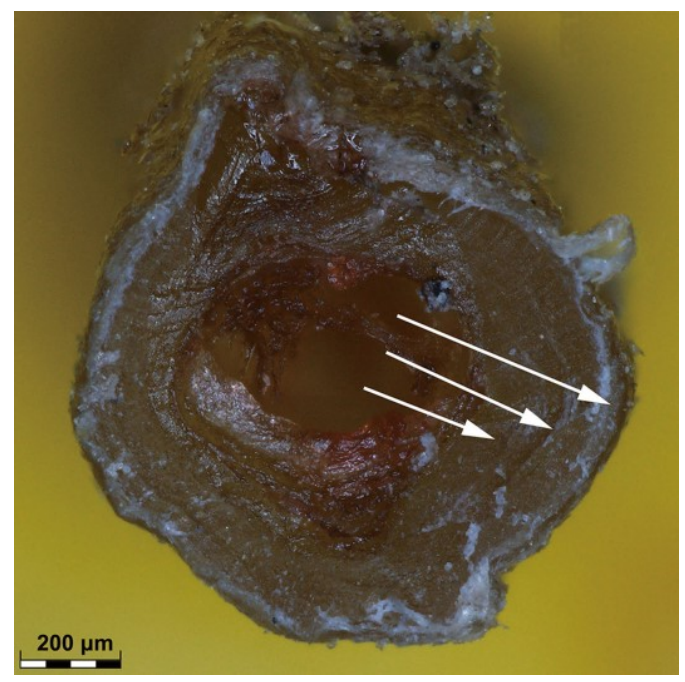

Fig. 4. Cross section in middle area of one papilla on plantar surface of $3^{\text {rd }}$ toe under light microscope. There are three circles resembling annual rings (three arrows) $(100 \times)$ 


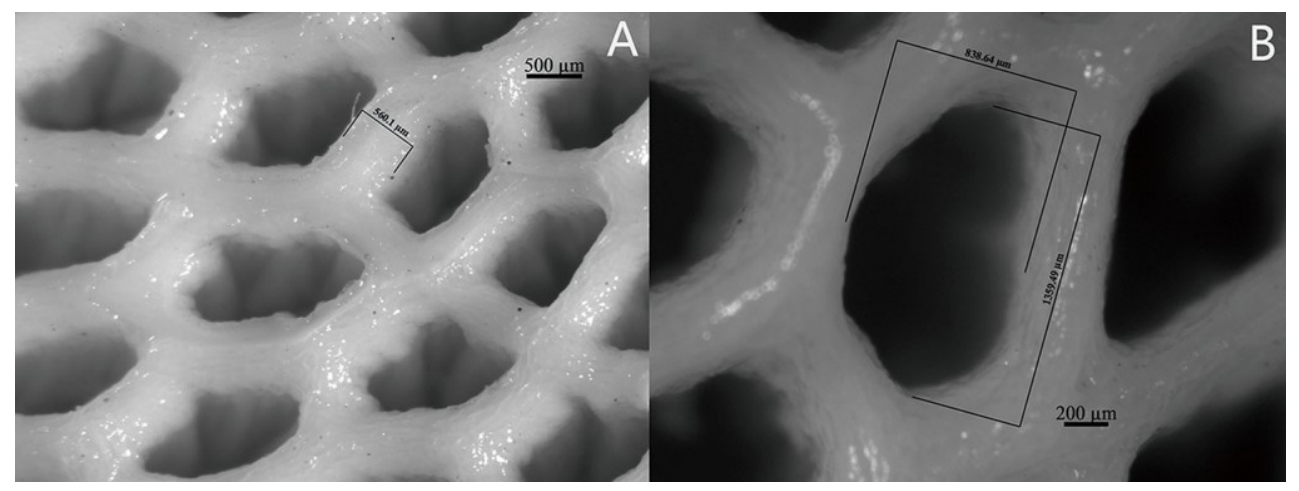

Fig. 5. SM photographs of initiation sites of papillae. A - 20×; B - 40×

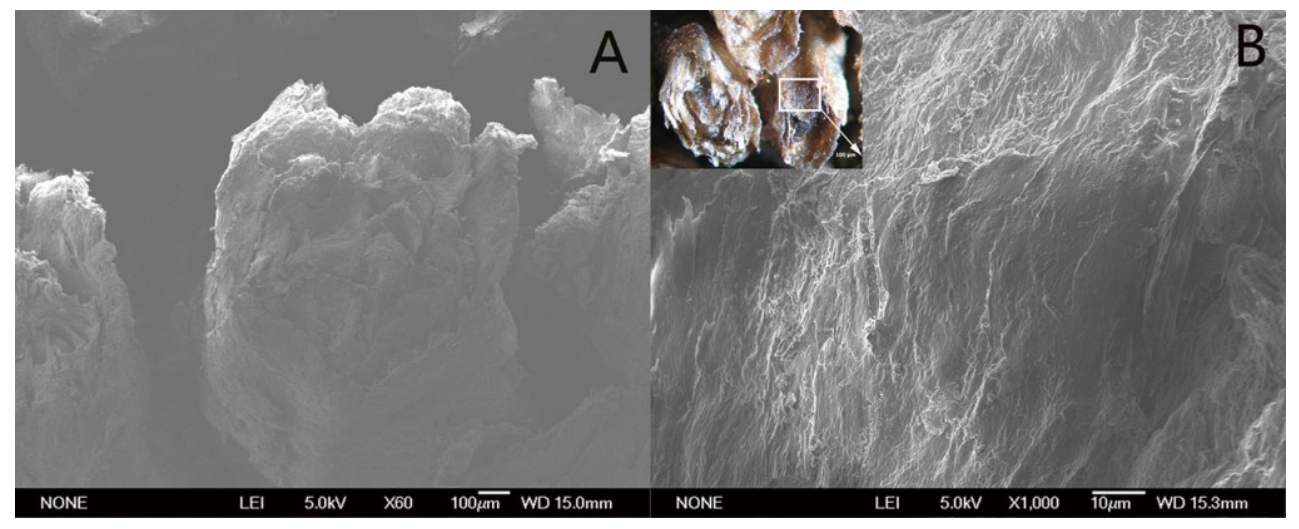

Fig. 6. SEM images of top papilla of $3^{\text {rd }}$ toe. A - surface profile of single papilla $(60 \times)$. B - surface of flat and layer-like structure on tip of $3^{\text {rd }}$ toe $(1000 \times)$

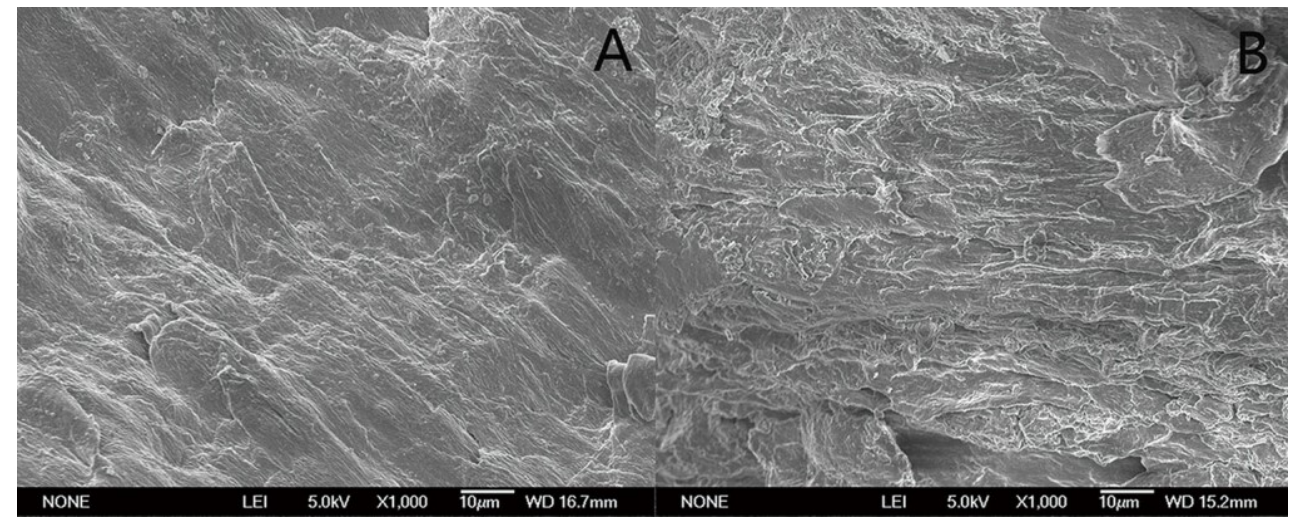

Fig. 7. SEM images of two parts of single papilla. A - middle part of a papilla on $3^{\text {rd }}$ toe $(300 \times)$; B - root of a papilla on $3^{\text {rd }}$ toe $(1000 \times)$

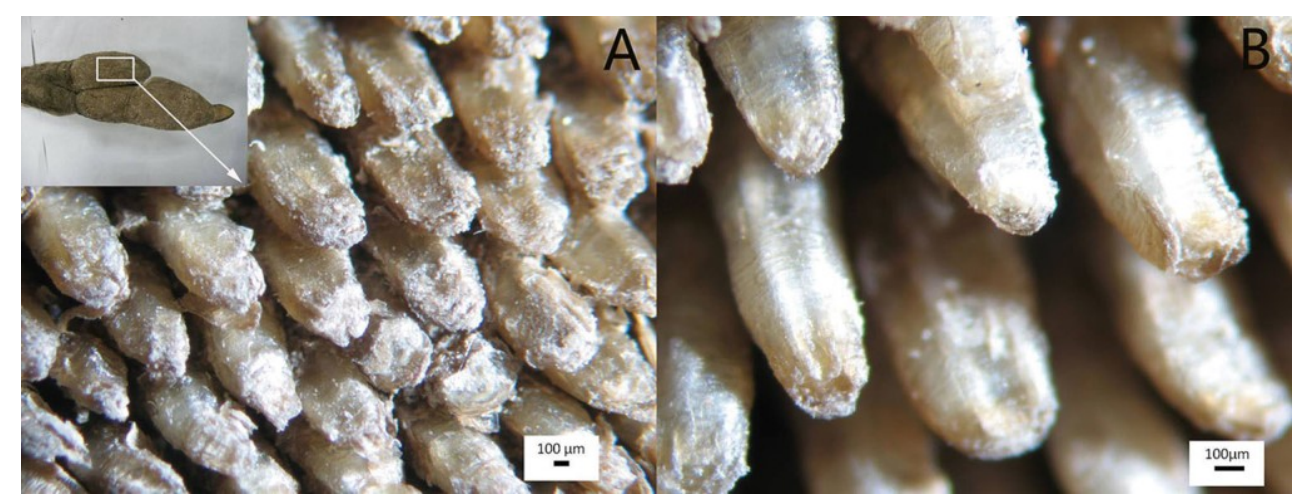

Fig. 8. SM photographs of papillae on $4^{\text {th }}$ toe. A - cone-shaped papillae (20×); B - unbroken tips (40×) 


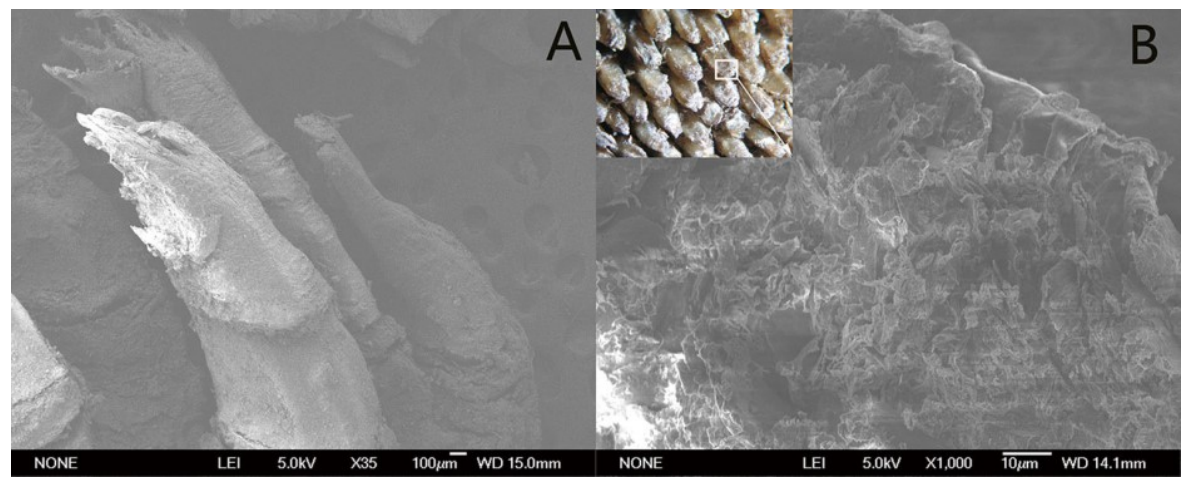

Fig. 9. SEM images of top of papilla of $4^{\text {th }}$ toe. A - surface profile $(35 \times)$; B - surface of disordered and rough structure on tip of $4^{\text {th }}$ toe $(1000 \times)$

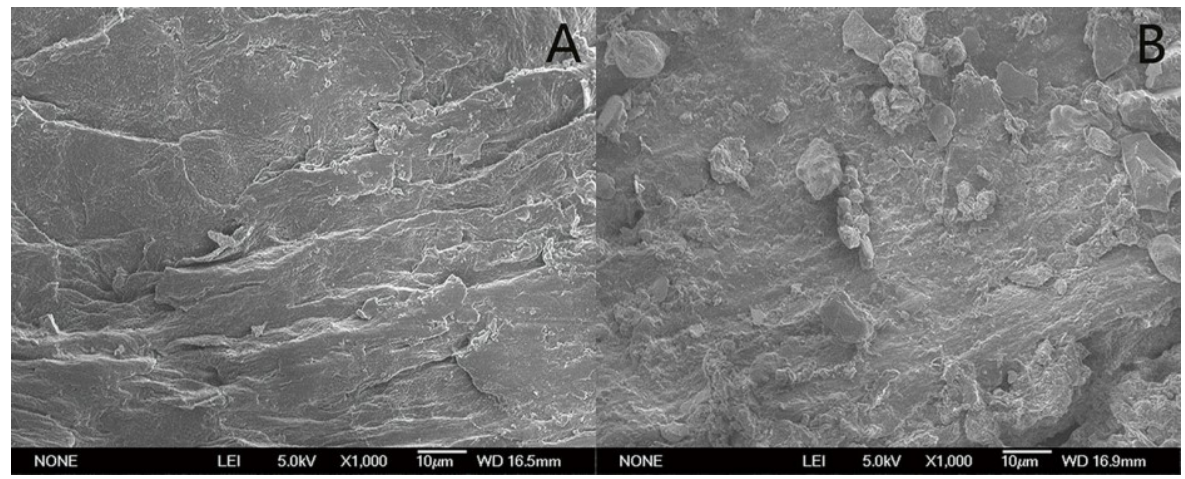

Fig. 10. SEM images of two parts of single papilla. A - middle part of papilla on the $4^{\text {th }}$ toe $(1000 \times)$; B root of papilla on $4^{\text {th }}$ toe $(1000 \times)$

The lateral region of the $3^{\text {rd }}$ toe. The lateral region of the $3^{\text {rd }}$ toe is a wide area with short circular convexes. In order to study in a more convenient manner, we divided it into three parts, which are the upper, middle, and bottom areas. Circular convex closures on the different parts displayed surfaces entirely different in shape, colour, and size. Integuments on the upper area are bright red and are comparatively flat circular convex closures just like the newly developed ones (Fig. 11A). However, the convex closures in the middle area show deeper red colouration and are a little taller than those in the upper area (Fig. 11B). Totally different from the above two areas, the bottom area is black and the top of the circular convexes reflect light (Fig. 11C). From the upper area to the bottom area, the integuments become taller, thinner, and more pointed. Observable in the corresponding SEM image is the upper area's uneven skin and irregular circular convexes (Fig. 11A_), whereas the bottom area emerges as a layer-like structure and shows a flat plane to some degree (Fig. 11C_). The structures in the middle area are the transitional region between the above two areas (Fig. 11B_). There are some layer structures and some wrinkles. CSLM images gauge the maximum height of the upper area to be $1100 \mu \mathrm{m}$, the middle $-1800 \mu \mathrm{m}$, and the bottom $-2000 \mu \mathrm{m}$ (Fig. 12). The higher the circular convexes are, the rougher the surface is.
Therefore, the surface roughness of the bottom area is greater than that of the upper area.

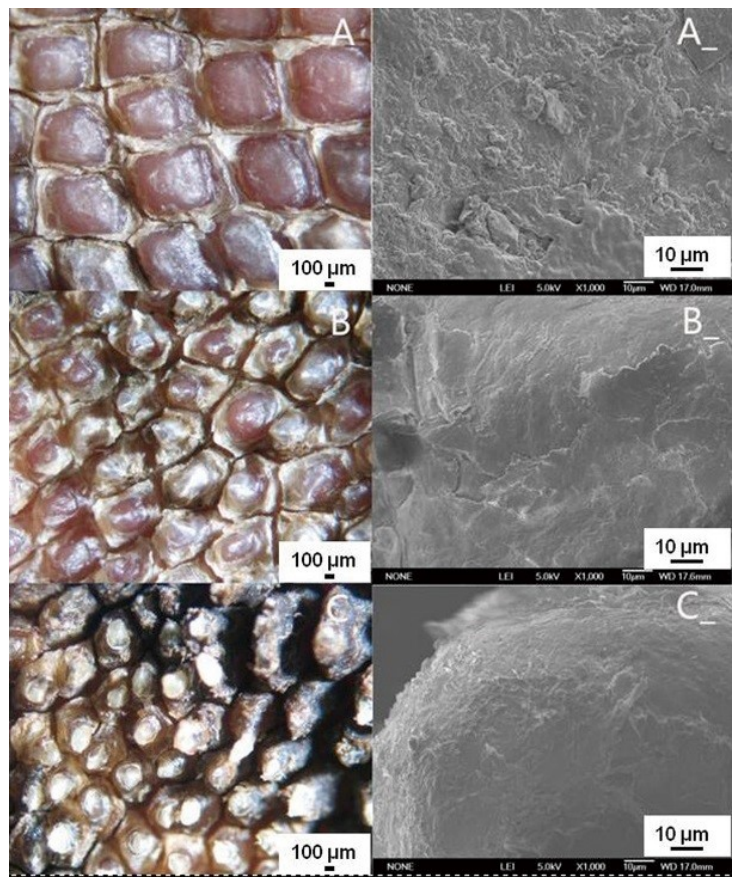

Fig. 11. SM photographs of lateral region of $3^{\text {rd }}$ toe and three SEM images of corresponding place on the left. A (A ) - upper area; $\mathrm{B}\left(\mathrm{B} \_\right.$) - middle area; $\mathrm{C}\left(\mathrm{C} \_\right.$) - bottom area. A, B, C - 20×, A, B , C $-1000 \times$ 


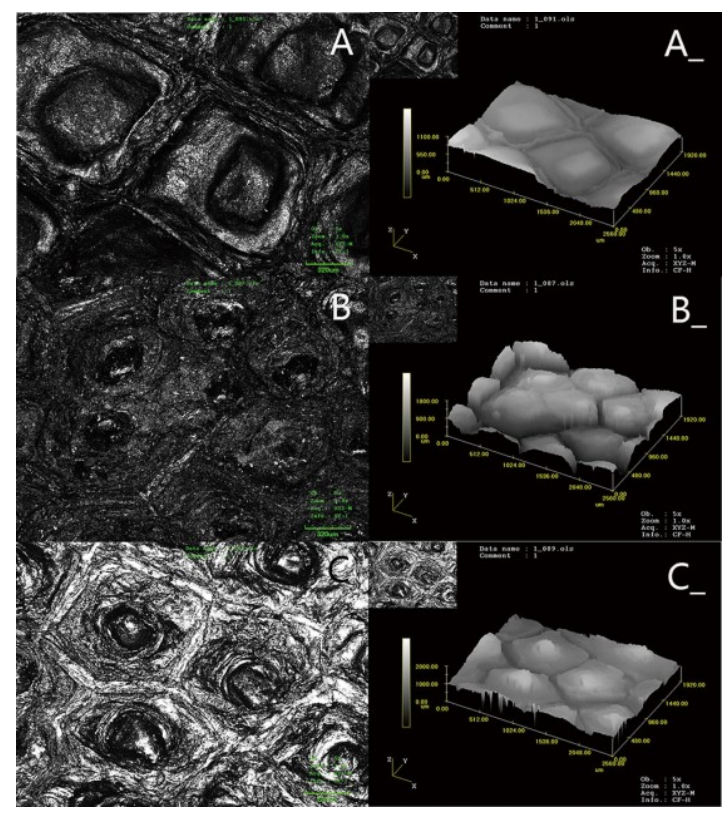

Fig. 12. CSLM images and corresponding three-dimensional images of Fig. 11

The transitional region between the $3^{\text {rd }}$ toe and the claw is a stretch of the lateral region of the $3^{\text {rd }}$ toe. As this area is narrow, we divided it into two parts: the upper and bottom areas. In the upper area, the integuments are light red. There is a covering layer of white material on the surface (Fig. 13A). In the bottom area, these covers become thin and discoloured. Integuments on the bottom are brown with light yellow covers on the surface (Fig. 13B). The corresponding SEM images of the upper area depict a flat plane with some small particles on it (Fig. 13A_). So this surface is somewhat rough. But the bottom area is very flat, relieved only by some stripes (Fig. 13B ). CSLM images allow the maximum height of the integuments on the upper area to be fixed at $1400 \mu \mathrm{m}$ and the maximum height of the integuments on the bottom area at $1800 \mu \mathrm{m}$ (Fig. 14). There is a rising tendency of surface roughness from the upper area to the bottom area and the size of the short circular convexes reduces and the density of the closures enlarges simultaneously.

Chemical element concentrations on the lateral region of the $3^{\text {rd }}$ toe. With the help of energy dispersive spectroscopy (EDS), the chemical element content
(Tables 1 and 2) of the integuments was collected from the tip of the lateral region of the $3^{\text {rd }}$ toe. Carbon and oxygen were undoubtedly the main two elements (upper area: $\mathrm{C}-57.93 \%$ and $\mathrm{O}-36.52 \%$; bottom area: $\mathrm{C}$ $75.75 \%$ and $\mathrm{O}-21.75 \%$ ). The content of some elements in the upper area $(\mathrm{Mg}-2.04 \%, \mathrm{Si}-0.18 \%, \mathrm{P}-1.97 \%$, $\mathrm{Ca}-0.59 \%$, and $\mathrm{S}-0.69 \%$ ) was higher than that of the bottom area $(\mathrm{Mg}-0.14 \%, \mathrm{Si}-0.09 \%, \mathrm{P}-0.10 \%, \mathrm{Ca}-$ $0.28 \%$, and $\mathrm{S}-0.90 \%$ ). Zinc was the specific element in the upper area. However, sodium, chlorine, and potassium were the specific elements in the bottom area.

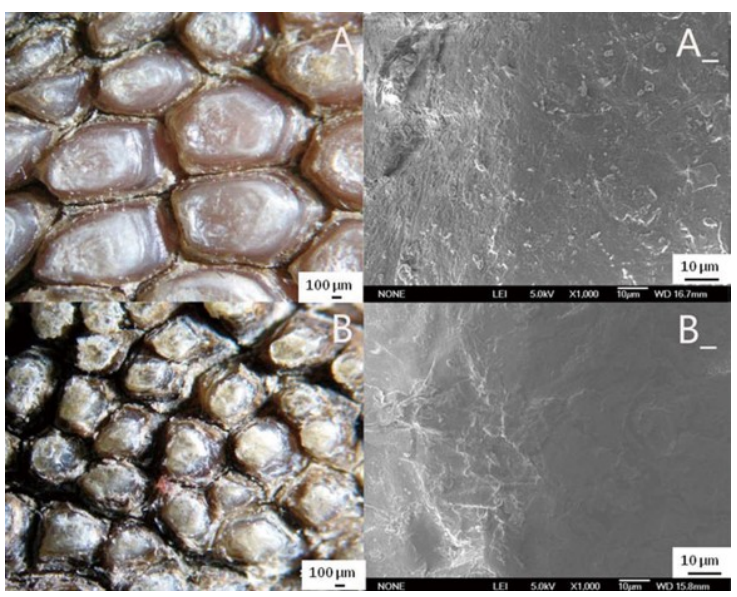

Fig. 13. SM photographs of transitional region between $3^{\text {rd }}$ toe and claw and two SEM images of corresponding places of left SM photographs. A (A ) - upper area; B (B ) - bottom area. A, B $-40 \times ;$ A, B_- $1000 \times$

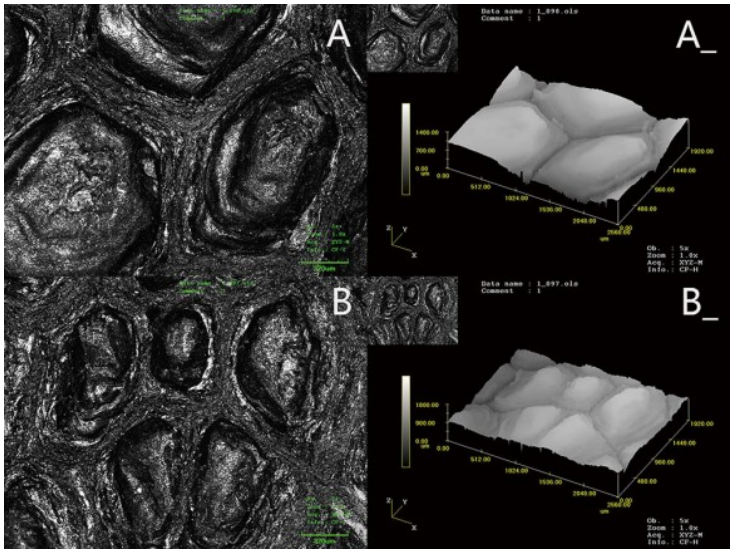

Fig. 14. CSLM images and corresponding three-dimensional images of Fig. 13

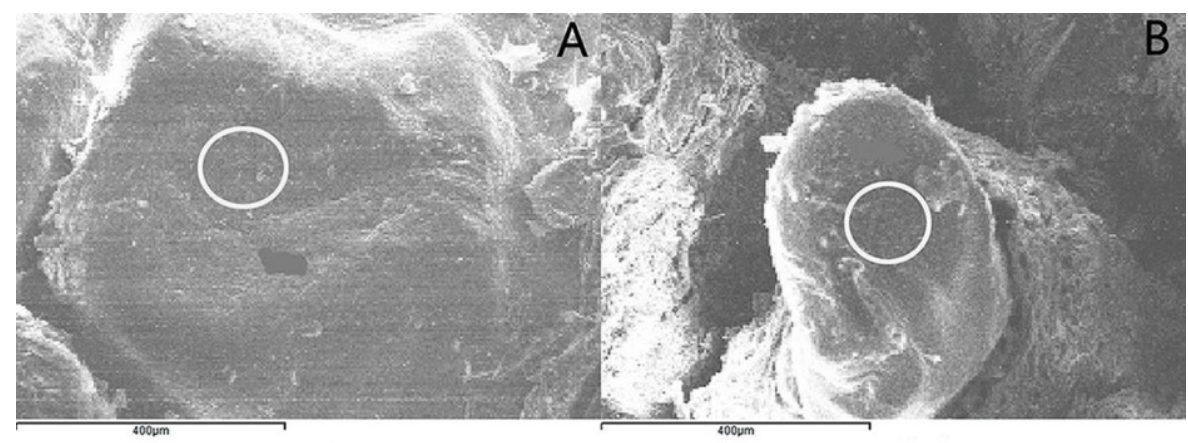

Fig. 15. Place of chemical element analysis (white circle). A - tip of short circular convex closure on upper area. B - short circular convex closure on bottom area 
Table 1. Contents of elements in upper area of the lateral region of $3^{\text {rd }}$ toe

\begin{tabular}{llllll}
\hline Element & $\begin{array}{l}\text { Element } \\
\text { concentration }\end{array}$ & $\begin{array}{l}\text { Intensity } \\
\text { corrections }\end{array}$ & Weight (\%) & $\begin{array}{l}\text { Weight (\%) } \\
\text { Sigma }\end{array}$ & Atom \\
\hline $\mathrm{C}$ & 32.64 & 0.8876 & 57.93 & 1.07 & 66.10 \\
$\mathrm{O}$ & 9.94 & 0.4284 & 36.52 & 1.08 & 31.28 \\
$\mathrm{Mg}$ & 0.93 & 0.7223 & 2.04 & 0.14 & 1.15 \\
$\mathrm{Si}$ & 0.10 & 0.8864 & 0.18 & 0.06 & 0.09 \\
$\mathrm{P}$ & 1.62 & 1.2904 & 1.97 & 0.13 & 0.87 \\
$\mathrm{~S}$ & 0.41 & 0.9278 & 0.69 & 0.08 & 0.30 \\
$\mathrm{Ca}$ & 0.36 & 0.9735 & 0.59 & 0.08 & 0.20 \\
$\mathrm{Zn}$ & 0.04 & 0.7412 & 0.08 & 0.34 & 0.02 \\
Total & & & 100.00 & & \\
\hline
\end{tabular}

Table 2. Contents of elements in bottom area of lateral region of $3^{\text {rd }}$ toe

\begin{tabular}{llllll}
\hline Element & $\begin{array}{l}\text { Element } \\
\text { concentration }\end{array}$ & $\begin{array}{l}\text { Intensity } \\
\text { corrections }\end{array}$ & Weight (\%) & $\begin{array}{l}\text { Weight (\%) } \\
\text { Sigma }\end{array}$ & Atom \\
\hline $\mathrm{C}$ & 39.74 & 1.2584 & 75.75 & 1.58 & 81.40 \\
$\mathrm{O}$ & 2.98 & 0.3279 & 21.75 & 1.55 & 17.54 \\
$\mathrm{Na}$ & 0.15 & 0.8275 & 0.44 & 0.15 & 0.25 \\
$\mathrm{Mg}$ & 0.05 & 0.7678 & 0.14 & 0.10 & 0.08 \\
$\mathrm{Si}$ & 0.03 & 0.9365 & 0.09 & 0.08 & 0.04 \\
$\mathrm{P}$ & 0.05 & 1.3418 & 0.10 & 0.09 & 0.04 \\
$\mathrm{~S}$ & 0.37 & 0.9731 & 0.90 & 0.12 & 0.36 \\
$\mathrm{Cl}$ & 0.10 & 0.8276 & 0.29 & 0.09 & 0.11 \\
$\mathrm{~K}$ & 0.11 & 1.0431 & 0.26 & 0.08 & 0.08 \\
$\mathrm{Ca}$ & 0.12 & 0.9742 & 0.28 & 0.08 & 0.09 \\
Total & & & 100.00 & & \\
\hline
\end{tabular}

\section{Discussion}

The back of the $3^{\text {rd }}$ toe being buried by sand simultaneously as the claw penetrates, wear-resistant scales can protect the toe from abrasion it would otherwise not avoid. What is more, the scales at the front side of the feet can protect them against the damage caused by stones or bushes during high-speed running. Tian et al. (19) found that rib morphology is one of the main coupling elements for the ability of biological material to resist wear. we believe this rib morphology contributes a good deal to the wearresistance of ostrich scales.

The $3^{\text {rd }}$ toe bears the main weight of the whole body and the $4^{\text {th }}$ toe just plays a role in assisting balance (17). The tip of the papilla on the $3^{\text {rd }}$ toe, integuments on the bottom area of the lateral region of the $3^{\text {rd }}$ toe, and integuments on the transitional region between the $3^{\text {rd }}$ toe and the claw are the main places to bear the large forces. These places are wear-resistant to protect the toe from injury and possess microscopically uncovered characteristics of relative smoothness with some layer-like structures and stripes. Therefore, we can infer that a microscopic plane with layer-like structure and stripes may contribute to the wearresistance of papillae.

The diameter of a single papilla on the $3^{\text {rd }}$ toe is about $740 \mu \mathrm{m}$ and the on $4^{\text {th }}$ toe is about $384 \mu \mathrm{m}$. That is to say, the heavier the supported weight is, the bigger the diameter needed. The growth mechanism of papillae is the same as that of the hair of mammals, which grows out from the root. Mammalian hair plays some common roles, such as keeping the mammal warm or disguising it to escape natural predators. It is easy to pull single mammalian hairs out from skin, but it is hard to pull ostrich papillae out. The papillae are essential for the ostrich to bear the pressure and shear force at every step, and they never exfoliate. The root of mammalian hair is cylindrical (15) but that of papillae is polygonal. So we can infer that the polygonal root may be firmer than the cylindrical.

The analytical data of the chemical elements is presented in the Tables 1 and 2. There is a difference between the two parts of the foot, which is that the content of some elements in the upper area was more than those of the bottom area. Zinc was the specific element in the upper area. Different chemical elements mean different compounds, and different surfaces with different wear-resistance are composed of different elements. Sodium, chlorine, and potassium are the specific elements in the bottom area. May be these elements enhance abrasive resistance.

Seeing the cross section image, the single papilla can be noticed to be hollow. However, the tubular structure is not aimed at reducing the body weight of the ostrich. The ostrich always lives in the desert where the temperature can reach more than $50^{\circ} \mathrm{C}$. This void may act as an isolating layer to prevent heat conduction. 
In this study, we applied imaging techniques to observe the macroscopic and microscopic structure of the foot integuments of the two-year-old ostrich. We conclude that the macroscopic and microscopic structure of papillae can be used for the design of some wear-resistant materials. In order to verify this, further investigations are needed, as intended by our research group.

Conflict of Interests Statement: The authors declare that they have no conflict of interests regarding the publication of this article.

Financial Disclosure Statement: The research has been funded by the National Natural Science Foundation of China (No. 51275199) and the Science and Technology Development Planning Project of Jilin Province of China (No. 20140101074JC).

Statement of Animal Rights: All procedures performed in studies involving animals were in accordance with the ethical standards of the institution or practice at which the studies were conducted.

\section{Reference}

1. Alexander R.M., Maloiy G.M.O., Njau R.: Mechanics of running of the ostrich (Struthio camelus). J Zool, London, 1979, 187, 169-178.

2. Alonso-Calleja C., Martinez-Fernández B., Capita R., Prieto M.: La carne de avestruz: valor nutritivo y calidad higiénica. Aliment Equipos Tecnol 2002, 21, 57-62.

3. Bonnan M.F., Sandrik J.L., Nishiwaki T., Wilhite D.R., Elsey R.M., Vittore C.: Calcified cartilage shape in archosaur long bones reflects overlying joint shape in stress-bearing elements: implications for nonavian dinosaur locomotion. Anat Rec 2004, 293, 2044-2055.

4. Brenesselová M., Koréneková B., Mačanga J., Marcinčák S., Jevinová P., Pipová M., Turek P.: Effects of vacuum packaging conditions on the quality, biochemical changes and the durability of ostrich meat. Meat Sci 2015, 101, 42-47.

5. Cooper A., Lalueza-Fox C., Anderson S., Rambaut A., Austin J., Ward R.: Complete mitochondrial genome sequences of two extinct moas clarify ratite evolution. Nature 2001, 409, 704-707.

6. Cooper R.G., Horbanczuk J.O.: Anatomical and physiological characteristics of ostrich (Struthio camelus var. domesticus) meat determine its nutritional importance for man. Anim Sci J 2002, $73,167-173$

7. Deeming D.C.: The ostrich - biology. In: Production and Health, edited by D.C. Deeming, Cambridge University Press, Cambridge, 2003.

8. El-Gendy S.A.A., Derbalah A., El-Magd M.E.R.A.: Macromicroscopic study on the toepad of ostrich (Struthio camelus). Vet Res Commun 2012, 36, 129-138.

9. El-Mahdy T., El-Nahla S.M., Abbott L.C., Hassan S.A.M.: Innervation of the pelvic limb of the adult ostrich (Struthio camelus). Anat Histol Embryol 2010, 39, 411-425.

10. Feduccia A.: Aves osteology. In: Sisson and Grossman's The Anatomy of the Domestic Animals, edited by Getty R., W.B. Saunders Company, Philadelphia, 1975, pp. 1790-1793.

11. Ferlazzo A.M., Campo G.M., Medica P., Calatroni A.: Characterization of serum 'glycosaminoglycan (GAG) chains'and 'native proteoglycan' fractions in the ostrich. Vet Res Commun 2003, 27 (1 supplement), 599-601.

12. Hallam M.G. Veterinary problems of ostriches. In: The Topaz Introduction to Practical Ostrich Farming, edited by M.G. Hallam, Harare, Zimbabwe, 1992. pp. 61-69.

13. Kent G.C., Carr R.K.: Comparative Anatomy of Vertebrates. McGraw Hill Higher Education, New York, 2001, pp. 179-182.

14. King A.S., McLelland J.: Birds, their Structure and Function Bailliere, Tindall, London, 1984, pp. 9-13, 24-26, 43-51.

15. Rogers G.E.: Hair follicle differentiation and regulation. Int J Dev Biol 2004, 48, 163-170.

16. Rubenson J., Lloyd D.G., Heliams D.B., Besier T.F., Fournier P.A.: Adaptations for economical bipedal running: the effect of limb structure on three-dimensional joint mechanics. J R Soc Interface 2011, 8, 740-755.

17. Schaller N.U., D’Août K., Villa R., Herkner B., Aerts P.: Toe function and dynamic pressure distribution in ostrich locomotion. J Exp Biol 2011, 214, 1123-1130.

18. Smith C.N., Payne R.C., Jespers K.J., Wilso A.M.: Muscle moment arms of pelvic limb muscles of the ostrich (Struthio camelus). J Anat 2007, 211, 313-324.

19. Tian L.M., Tian X.M., Wang Y.C., Hu G.L., Ren L.Q.: Antiwear properties of the molluscan shell Scapharca subscrenata: influence of surface morphology, structure and organic material on the elementary wear process. Mat Sci Engin C 2014, 42, $7-14$.

20. Tomiosso T.C., Gomes L., Vidal B.C., Pimentel E.R.: Extracellular matrix of ostrich articular cartilage. Biocell 2005, $29,47-54$.

21. Mosauer W.: Adaptive convergence in the sand reptiles of the Sahara and of California: A study in structure and behavior. Copeia, 1932, 2, 72-78.

22. Weissengruber G.E., Forstenpointner G., Gangl D.: Gut zu Fuß-funktionell-anatomische Aspekte des bipeden Laufens beim Afrikanischen Strauß (Struthio camelus Linné, 1758). Vet Med Austria/Wien Tierärztl Mschr 2003, 90, 67-78. 